\title{
EFFECT OF COPPER ON ISOLATED RABBIT BLASTOCYSTS
}

\author{
M. H. CROSS \\ Laboratory of Reproductive Physiology, School of Veterinary Medicine, \\ University of Pennsylvania, Philadelphia, Pennsylvania 19104, U.S.A.
}

(Received 13th Fune 1972)

The addition of metallic copper to an IUD has been shown to enhance its contraceptive effectiveness (Zipper, Tatum, Pastene, Medel \& Rivera, 1969). A change occurs in the intrauterine environment (Chang, Tatum \& Kincl, 1970), which may interfere with the development of the blastocyst. Since copper may act directly on the free-lying blastocyst, its effect was studied on the electrical membrane properties of the isolated-perfused 6-day rabbit blastocyst.

Blastocysts (2 to $3 \mathrm{~mm}$ average diameter) were collected and perfused as previously described (Cross, 1971) in an environmental chamber (Cross \& Brinster, 1970) designed to secure the embryo during manipulations and maintain constant temperature $\left(37^{\circ} \mathrm{C}\right)$, humidity and gas phase $\left(5 \% \mathrm{CO}_{2}\right.$ in air). Electrical measurements, made by techniques described previously (Cross, 1971), included short-circuit current (SCC), transmural potential difference (p.d.) and conductance. Values of SCG were recorded continuously except when the external current was briefly opened to obtain values of p.d. Conductance was computed from the ratio of open circuit p.d. to SCG since the blastocoele wall behaves as a simple linear resistor (Cross, 1971). Blastocysts were perfused and bathed with the same solution (Krebs-Ringer bicarbonate containing $1 \mathrm{mg}$ bovine serum albumin $/ \mathrm{ml}$ ) to eliminate concentration gradients or chemical forces. The p.d. across the blastocoele wall was reduced to zero by passing current from an external source. This removes electrical forces acting on ions. Under these short-circuit conditions, no electrochemical gradient exists, no net passive transfer of ions takes place, and the SCG is the resultant of the currents produced by all the net active ionic transport processes. After complete replacement of the blastocoele cavity with the bathing solution, the p.d. and SCC progressively increase, reaching steady values by 40 to $60 \mathrm{~min}$. Once attained, the electrical parameters were stable $( \pm 5 \% / \mathrm{hr}$ ) for 3 to $4 \mathrm{hr}$. Steady electrical parameters (mean \pm S.E.) of twenty blastocysts maintained up to $4 \mathrm{hr}$ were as follows: p.d. was $-13.2 \pm 0.6 \mathrm{mV}$, blastocoele cavity negative; SCC was $5.3 \pm 0.2 \mu \mathrm{A} / \mathrm{cm}^{2}$; conductance was 0.4 $\mathrm{mmho} / \mathrm{cm}^{2}$.

Text-figure 1 and Table 1 show the results of nine experiments in which serial additions of $\mathrm{CuCl}_{2}$ were added to the bathing solution. Each serial addition was a 10- $\mu$ l aliquot of a stock solution of $\mathrm{CuCl}_{2}$ prepared in KrebsRinger solution. Similar serial additions of Krebs-Ringer solution to twenty 


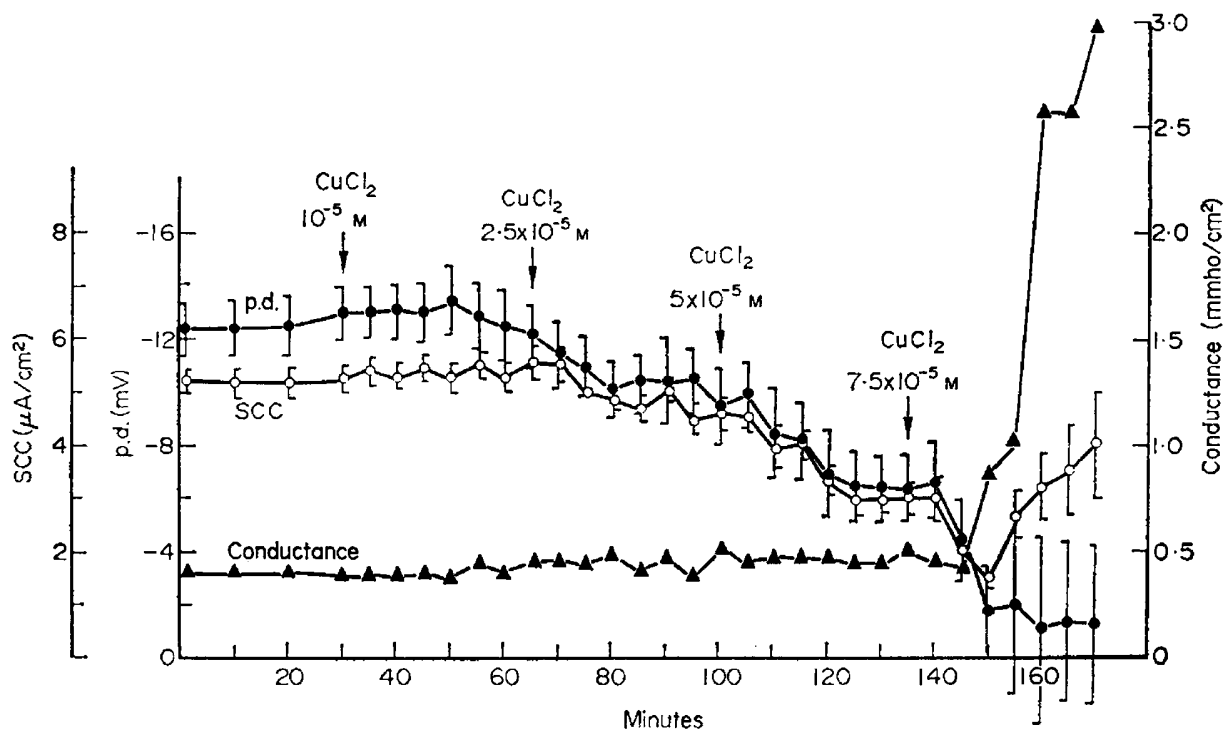

TeXT-FIG. 1. Effects of $\mathrm{CuCl}_{2}$ on short-circuit current (SCG), potential difference (p.d., blastocoele cavity negative with respect to outside solution) and conductance of the rabbit blastocoele wall. Serial additions of $\mathrm{CuCl}_{2}$ were made to the outside solution. Arrows indicate time of addition of $\mathrm{CuCl}_{2}$ to reach the final concentrations noted above the arrows. Each point represents mean \pm S.E. of nine blastocysts obtained from nine rabbits.

blastocysts, used to determine steady electrical parameters, produced no significant changes in the electrical values. After a control period of $30 \mathrm{~min}$ (each embryo was its own control), when stable SCG and p.d. readings were obtained, the addition of $\mathrm{CuCl}_{2}, 10^{-5} \mathrm{M}$ final concentration, caused no significant change in any of the electrical parameters. When the concentration of copper in the outside solution was increased to $2.5 \times 10^{-5} \mathrm{M}$, a reduction in the average p.d. $(25 \%)$ and average SCC $(12 \%)$ was seen after $30 \mathrm{~min}$. During the sub-

Table 1. Changes in potential difference and short-circuit current across the blastocyst wall with serial additions of $\mathrm{CuCl}_{2}$ to the outside bathing solution

\begin{tabular}{|c|c|c|c|}
\hline Treatment & $\underset{(\min )}{\text { Time }}$ & $\begin{array}{l}p . d . \\
(m V)\end{array}$ & $\begin{array}{c}S C C \\
\left(\mu A / \mathrm{cm}^{2}\right)\end{array}$ \\
\hline $\begin{array}{r}\text { Control } \\
10^{-5} \mathrm{M}-\mathrm{CuCl}_{2} \\
2.5 \times 10^{-5} \mathrm{M}-\mathrm{CuCl}_{2} \\
5.0 \times 10^{-5} \mathrm{M}-\mathrm{CuCl}_{2} \\
7.5 \times 10^{-5} \mathrm{M}-\mathrm{CuCl}_{2} \\
7.5 \times 10^{-5} \mathrm{M}-\mathrm{CuCl}_{2}\end{array}$ & $\begin{array}{l}30 \\
30 \\
30 \\
10 \\
30\end{array}$ & $\begin{array}{l}-12.5 \pm 1.0 \\
-12.2 \pm 1.1 \\
-9.4 \pm 1.4 \\
-6.5 \pm 1.2^{* * *} \\
-1.9 \pm 1.6^{* * *} \\
-1.4 \pm 1.5^{* * *}\end{array}$ & $\begin{array}{l}5.25 \pm 0.45 \\
5.62 \pm 0.59 \\
4.74 \pm 0.67 \\
3.27 \pm 0.65 * \\
1.57 \pm 0.41 * * * \\
4.07 \pm 1.97\end{array}$ \\
\hline
\end{tabular}

For abbreviations, see text. Mean values \pm S.E. are given for nine blastocysts.

+ Time after final concentration was reached.

$\ddagger$ Average of three 10 -min control periods before addition of $\mathrm{CuCl}_{2}$.

* $P<0.02$ when compared with control.

** $P<0.01$ when compared with control.

***P<0.001 when compared with control. 


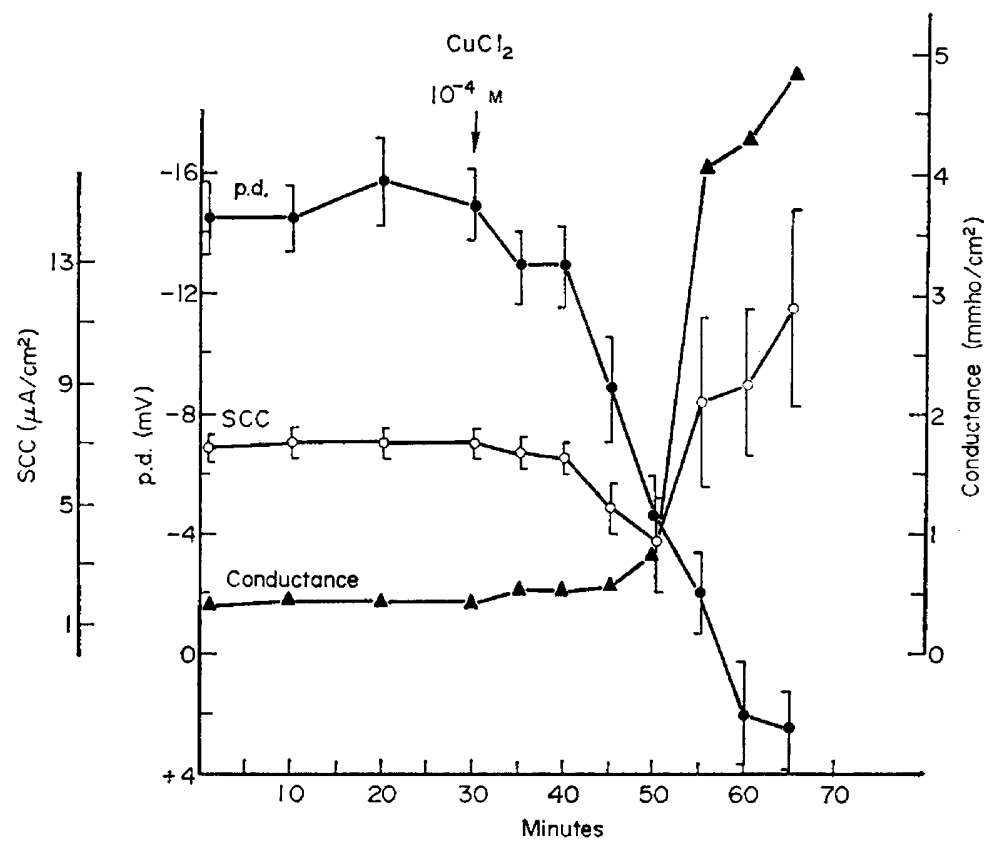

TEXT-FIG. 2. Effects of $\mathrm{CuCl}_{2}$ on SGC, p.d. and conductance of the rabbit blastocoele wall. Arrow indicates time at which $10^{-4} \mathrm{M}_{-} \mathrm{CuCl}_{2}$ was added to the outside solution. Each point represents mean \pm S.E. of nine blastocysts obtained from nine rabbits.

sequent $\mathrm{CuCl}_{2}$ applications, a final concentration of $5 \times 10^{-5} \mathrm{M}$ further decreased p.d. (48\%) and SCG (38\%) after an additional $30 \mathrm{~min}$; after a final concentration of $7.5 \times 10^{-5} \mathrm{M}$ was reached, the p.d. was greatly depressed $(89 \%)$ within $10 \mathrm{~min}$, a third of the p.d. values being positive. The absolute magnitude of the average SCC continued to decrease $(71 \%)$ and then increased during the next $20 \mathrm{~min}$ to $77 \%$ of control values. The subsequent changes in p.d. and SCC caused a sixfold increase in membrane conductance.

Table 2. Changes in potential difference and short-circuit current across the blastocyst wall when $\mathrm{CuCl}_{2}$ is added to outside bathing solution

\begin{tabular}{|c|c|c|c|}
\hline Treatment & $\underset{(\min )}{\text { Time† }}$ & $\underset{(m V)}{p \cdot d .}$ & $\begin{array}{c}S C C \\
\left(\mu A / \mathrm{cm}^{2}\right)\end{array}$ \\
\hline $\begin{array}{l}\text { Control } \ddagger \\
10^{-4} \mathrm{M}-\mathrm{CuGl}_{2} \\
10^{-4} \mathrm{M}-\mathrm{CuGl}_{2} \\
10^{-4} \mathrm{M}-\mathrm{CuGl}_{2} \\
10^{-4} \mathrm{M}-\mathrm{CuCl}_{2} \\
10^{-4} \mathrm{M}-\mathrm{CuCl}_{2} \\
10^{-4} \mathrm{M}-\mathrm{CuCl}_{2}\end{array}$ & $\begin{array}{l}10 \\
15 \\
20 \\
25 \\
30 \\
35\end{array}$ & $\begin{array}{l}-14.5 \pm 1.2 \\
-12.9 \pm 1.3 \\
-8.9 \pm 1.5 * * \\
-4.7 \pm 1.3 * * * \\
-2.0 \pm 1.4 * * * \\
+2.1 \pm 1.7 * * * \\
+2.4 \pm 1.2 * * *\end{array}$ & $\begin{array}{c}7.00 \pm 0.43 \\
6.58 \pm 0.50 \\
4.94 \pm 0.87 \\
3.78 \pm 1.00 * * \\
8.35 \pm 1.50 \\
9.05 \pm 2.00 \\
11.55 \pm 1.40 * *\end{array}$ \\
\hline
\end{tabular}

For abbreviations, see text. Mean values \pm S.E. are given for nine blastocysts.

+ Time after addition of $10^{-4} \mathrm{M}-\mathrm{CuCl}_{2}$.

$¥$ Average of three 10 -min control periods before addition of $\mathrm{CuCl}_{2}$.

** $P<0.01$ when compared with control.

*** $P<0.001$ when compared with control. 
Text-figure 2 and Table 2 show the results of nine experiments involving a second group of blastocysts. The effects of a single addition of $\mathrm{CuCl}_{2}\left(10^{-4} \mathrm{M}\right)$ on the electrical properties of the blastocoele wall were studied. The average p.d. continued to decrease during exposure to copper, with a reversal to positive values after $30 \mathrm{~min}$. A biphasic response of SCG was observed, similar to that for $7.5 \times 10^{-5} \mathrm{M}^{-\mathrm{CuCl}_{2}}$. The absolute magnitude of SCG decreased $(46 \%)$ after $20 \mathrm{~min}$ and then increased by $35 \mathrm{~min}$ to a value 1.7 times that of the control values. The resultant increase in membrane conductance was about tenfold. The effects seen in the two types of experiments performed (Text-figs 1 and 2) were not reversible when copper was removed from the outside solution. In addition, the majority of blastocysts exposed to $10^{-4} \mathrm{M}_{-} \mathrm{CuCl}_{2}$ began to collapse after their return to copper-free solution, while three of nine embryos were only slightly collapsed after exposure to the serial additions of copper.

We recently demonstrated, using the short-circuit preparation simultaneously with isotope flux, that the 6-day rabbit blastocyst actively transports $\mathrm{Na}^{+}$and $\mathrm{Cl}^{-}$at about the same rate from the bathing solution to the blastocoele cavity (Cross, 1973). The same experiments strongly suggest that $\mathrm{HCO}_{3}-$ is actively transported in the same direction. The present results do not indicate which of the active ionic transport processes copper affects, but concentrations of $2.5 \times$ $10^{-5}$ and $5 \times 10^{-5} \mathrm{M}$ decrease SCC without greatly affecting conductance. This suggests an alteration of at least one of the active ionic transport processes at lower concentrations of copper.

The effects of copper at higher concentrations $\left(7.5 \times 10^{-5}\right.$ and $\left.10^{-4} \mathrm{M}\right)$ appear to be more complex, resulting in a biphasic response. In the first phase, the active ionic transport processes across the blastocoele wall are changed (SCG decreases) as in the case for lower copper concentrations. In the second phase, SCC is stimulated and membrane conductance is greatly increased. A decrease in SCC could indicate an increase in the cation component of SCC, a decrease in anion transport, or a differential inhibition or stimulation of cation and anion transport. An increase in SCG would result from the reverse conditions. To identify which specific actively transported ions are affected by copper and to determine the nature of the effects on passive ionic permeability (conductance), simultaneous short-circuit current-isotope flux experiments, carried out under the same conditions as the present experiments, are needed. The collapse noted after exposure to higher $\mathrm{CuCl}_{2}$ concentrations, and the large increase in membrane conductance, suggest that longer term effects under our experimental conditions would be toxic and would probably evoke conformational changes of membranes.

In other in-vitro epithelium preparations, addition of copper $\left(10^{-5}\right.$ to $\left.10^{-4} \mathrm{M}\right)$ has been shown to increase ${ }^{36} \mathrm{CI}^{-}$permeability but to decrease its net transport (Ferreira, 1970), to decrease ${ }^{36} \mathrm{Cl}^{-}$influx without effect on SCG and ${ }^{22} \mathrm{Na}^{+}$ fluxes (Koefoed-Johnsen \& Ussing, 1958) and to stimulate $\left(10^{-5}\right.$ to $10^{-4} \mathrm{M}$ ) active $\mathrm{Na}^{+}$transport (Ferreira, 1970; Brunton, 1972).

Since active ionic transport must be directly related to the accumulation of blastocoele fluid, factors altering these ionic transport processes could inhibit blastocyst expansion. The action of copper noted here may have some bearing on the effectiveness of the copper-containing IUD as a contraceptive agent. 
This research was supported by the Center for Population Research, NIH Contract 69-2141. The expert technical assistance of Miss Cynthia Livak is gratefully acknowledged.

\section{REFERENCES}

Brunton, W. J. (1972) Copper stimulation of $\mathrm{Na}$ transport across the isolated rabbit oviduct. Fedn Proc. Fedn Am. Socs exp. Biol. 31, 2128.

Ghang, C. C., Tatum, H. J. \& Kinci, F. A. (1970) The effect of intrauterine copper and other metals on implantation in rats and hamsters. Fert. Steril. 21, 274.

CRoss, M. H. (1971) Rabbit blastocoele perfusion technique. Nature, Lond. 232, 635.

Cross, M. H. (1973) Active sodium and chloride transport across the rabbit blastocoele wall. Biol. Reprod. (in press).

CRoss, M. H. \& BrINster, R. L. (1970) Influence of ions, inhibitors and anoxia on transtrophoblast potential of rabbit blastocyst. Expl Cell Res. 62, 303.

Ferreira, K. T. G. (1970) The effect of copper on isolated frog skin. Biochim. biophys. Acta, 203, 555.

Koefoed-Johnsen, V. \& Ussing, H. H. (1958) The nature of the frog skin potential. Acta physiol. scand. 42, 298.

Zipper, J. A., Tatum, H. J., Pastene, L., Medei, M. \& Rivera, M. (1969) Metallic copper as an intrauterine contraceptive adjunct to the 'T' device. Am. F. Obstet. Gynec. 105, 1274. 